\title{
Isolamento de Microsporum \\ amazonicum do solo do Estado do A.mazonas, Brasil
}

\author{
Aurélia Lopes Castrillón ( $\left.{ }^{\star}\right)$ \\ Mário Augusto Pinto de Moraes (**) \\ Maria do Socorro Souza Furtado (")
}

\section{Resumo}

Do solo de uma gruta, localizada no $\mathrm{Km} 130$ da Estrada Manaus-Caracaraí, isolou-se o dermatófito Microsporum amazonicum, que até entâo navia sido encontrado apenas no pêlo de animais silvestres. Em 3 coletas feitas, com intervalos de alguns meses, durante o ano de 1974, recolheram-se 96 amostras de terra do chão da gruta, das quais 12 , ou seja, $12,5 \%$ foram positivas para o fungo. São discutidas no trabalho as razōes que tornam difícil o isolamento de M. amazonicum do solo, apesar de ser ele, aparentemente, um fungo ceratinofílico próprio da regiāo amazônica.

\section{INTRODUÇÃo}

Microsporum amazonicum, espécie descrita por Moraes et al. (1967), é um fungo dermatófilo bastante raro, que até agora, tem sido encontrado apenas no pelo de roedores siivestres da região amazônica. Sua presença no solo, embora presumível, ainda não havia sido demonstrada, apesar dos vários trabalhos sobre ceratinófilos já efetuados na região. Mes mo a forma perfeita do fungo, recentemente obtida por Moraes et al. (1975), resultou de isolamentos feitos a partir do pêlo de ratos silvestres, capturados nos arredores de Belém, Estado do Pará.

O propósito deste trabalho é comunicar o achado, pela primeira vez, desse dermatófilo no solo de uma gruta localizada à margem esquerda da Rodovia Manaus-Caracaraí, Estado do Amazonas.

\section{MATERIAL E MÉTODOS}

A gruta de onde se colheu as amostras de solo"está no Km 130 da Rodovia BR-174 (Manaus - Caracaraí), dentro da mata virgem cerca de 50 metros do leito da estrada. Seu interior consta de dois compartimentos circulares (Fig. 1) com paredes de pedras nas quais existem diversos refúgios ou tocas, utilizados por animais de hábitos noturnos. O local é bastante escuro, tendo exigido o uso de lanternas para o trabalho de coleta. No solo, arenoso e úmido, encontrou-se diversas poças d'água.

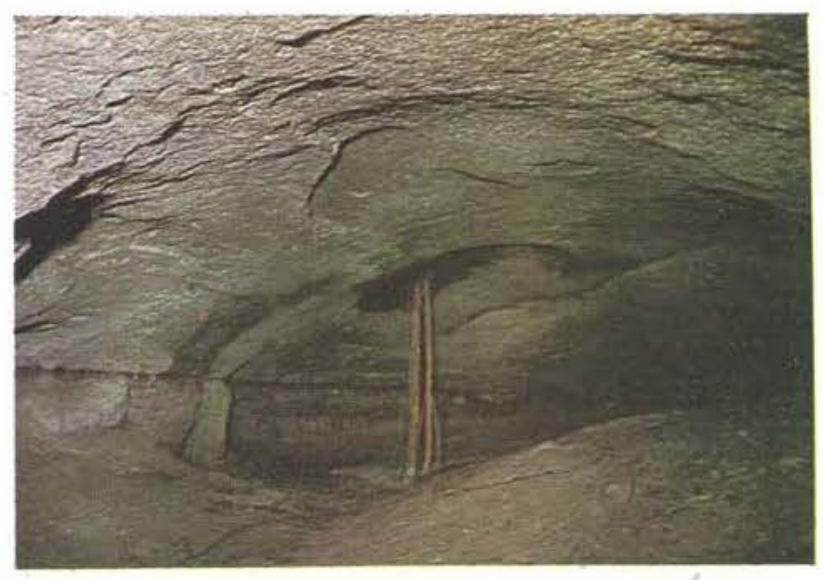

Fig. 1 - Gruta de onde foi coletado o solo.

Ao todo, 96 amostras foram colhidas, em três épocas diferentes. A primeira coleta, feita em março de 1974, constou de 30 amostras, sendo 15 do interior da gruta, 10 da entrada e 5 do lado de fora. A segunda coleta, realizada no mês de julho, produziu 55 amostras: 25 do interior, 20 da entrada e 10 das proximidades. Na terceira coleta, levada a cabo em dezembro, recolheram-se apenas 11 amos. tras, todas do chão dos dois compartimentos

(") - Instituto Nacional de Pesquisas da Amazônia, Manaus. (*) - Instituto Evandro Chagas, Belém. 
Por ocasião das três coletas, as condições dentro da gruta eram muito semelhantes: a temperatura variou de 28 a $29 .^{\circ} \mathrm{C}$, e a unidade relativa, de 92 a $98 \%$.

No isolamerito dos fungos, empregou-se a técnica bem conhecida de Vanbreuseghem (1952), para ceratinófilos do solo: sobre as amostras de terra, em placas de Petri, colocam-se fragmentos de cabelos humanos previamente esterilizados, que servem de "isca" aos fungos capazes de utilizar a ceratina. As preparaçōes assim obtidas, com as amostras da gruta, foram conservadas no laboratório do INPA, à temperatura ambiente, durante um período de 90 dias, tendo-se o cuidado de não deixá-las secar. Para tanto, algumas gotas de água destilada estéril eram adicionadas, semanalmente, à terra das piacas. Os fungos, à medida que se desenvolviam sobre os cabelos, eram transferidos para o meio de Sabouraud (Sabouraud-dextrose-ágar), contendo cloranfenicol (250 mg/1.000 ml. de meio) e Actidione (500 mg/1.000 ml de meio), e posteriormente identificados, quando possível.

\section{Resultados}

O Microsporum amazonicum desenvolveuse em 12 placas, ou seja em $12 \%$ das amostras estudadas. O crescimento teve início, em geral, entre $27 .^{\circ}$ e o $60 .^{\circ}$ dias, após a preparação das placas. Somente aquelas amostras colhidas no interior e na entrada da gruta mostraram-se positivas.

De acordo com a época da coleta, o número relativo mais alto de amostras positivas ocorreu no mês de março. Para as três coletas, os percentuais de positividade foram respectivamente: $16 \%, 11 \%$ e $9 \%$.

Além de $M$. amazonicum, vários outros fungos, a maioria constituída por contaminantes, cresceram também no interior das placas. Constam eles dos quadros I, II e III. M. amazonicum, entretanto, foi o único ceratinófilo encontrado.

\section{COMENTÁRIO\$}

Sobre $M$. amazonicum, dois fatos interessantes, embora ainda não definitivos, merecem aqui referência: sua distribuição limitada à re- gião amazônica e sua raridade no solo lestá mais comumente associado ao pêlo de animais silvestres).

Quadro I - Fungos isolados na primeira coleta

\begin{tabular}{l|cc}
\cline { 2 - 3 } \multicolumn{1}{c}{ Gênero } & \multicolumn{2}{c}{ Amostras: 30 } \\
\cline { 2 - 3 } \cline { 3 - 3 } Cephalosporium sp. & Ocorrência & $\%$ \\
Mycelia sterila & 7 & 20.0 \\
M. amazonicum & 5 & 45.7 \\
Penicillium sp. & 2 & 14.30 \\
Verticillium sp. & 3 & 5.70 \\
Fungos não identificados & 2 & 8.60 \\
\hline
\end{tabular}

Quadro II - Fungos isolados do solo na 2.a coleta

\begin{tabular}{l|cc}
\hline \multirow{2}{*}{ Gênero } & \multicolumn{2}{|c}{ Amostras: 30 } \\
\cline { 2 - 3 } \cline { 2 - 3 } & Ocorrência & \multicolumn{1}{c}{$\%$} \\
\hline Aspergillus sp. & 15 & 16.30 \\
Cephalosporium sp. & 2 & 2.17 \\
Cuninghamella sp. & 1 & 1.10 \\
Fusarium sp. & 4 & 4.35 \\
Geotrichum sp. & 2 & 2.17 \\
Leveduras & 2 & 2.17 \\
Mycelia sterila & 26 & 28.26 \\
Viiicrosporum amazonicum & 6 & 6.52 \\
Penicillium sp. & 8 & 8.70 \\
Verticillium sp. & 3 & 3.26 \\
Fungos não identificados & 23 & 23.0 \\
\hline
\end{tabular}

Quadro III - Fungos isolados do solo na 3.a coleta

\begin{tabular}{l|cc}
\hline \multirow{2}{*}{ Gênero } & \multicolumn{2}{c}{ Amostras: 11 } \\
\cline { 2 - 3 } Cephalosporium sp. & Ocorrências & $\%$ \\
Fusarium sp. & 4 & 11.46 \\
Geotrichum sp. & 1 & 2.85 \\
Leveduras & 3 & 5.70 \\
Viicrosporum amazonicum & 1 & 8.57 \\
Miycelia sterila & 3 & 2.85 \\
Penicillium sp. & 6 & 8.57 \\
Verticillium sp. & 1 & 17.15 \\
Fungos não identificados & 14 & 2.85 \\
\hline
\end{tabular}




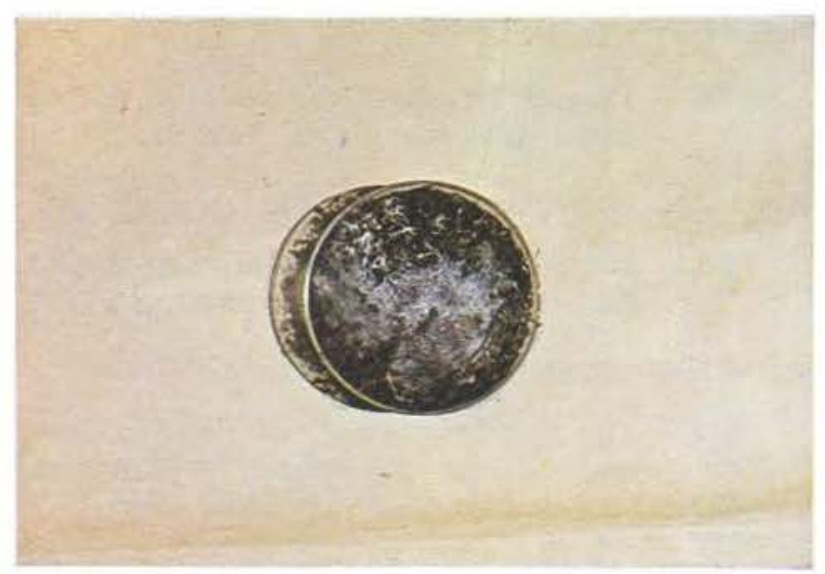

Fig. 2 - Microsporum amazonicum. Crescimento em "isca" de cabelo.

A descrição deste fungo, feita em 1967, teve por base duas culturas obtidas por Moraes et al. (1967), do pêlo de dois ratos silvestres do gênero Oryzomys, capturados perto da cidade de Manaus, Estado do Amazonas. Os aspectos culturais do $M$. amazonicum e principalmente de seus macroconídios fusiformes. com 1 a 3 septos, numerosos e bem característicos, năo deixam dúvida e permitem distinguir esta espécie, com facilidade, das outras do mesmo gênero. Tanto é assim que, logo no ano seguinte, foi ela incluída por Ajello (1968). em uma lista dos dermadófitos conhecidos na época, que o referido autor fez publicar.

Apesar disso, até hoje não se teve notícia do achado desse cogumelo em outros Estados do Brasil ou mesmo fora do país. Ao que tudo indica, este é um fungo de distribuição geográfica limitada, que ocorre, por motivo qualquer, associado apenas ao solo da mata da regiẫo amazônica.

Por outro lado, apesar dos vários trabathos sobre fungos geofílicos já levados na região (Ozório, 1976 e Vilela, 1962), esta é a primeira vez que o $M$. amazonicum é assinalado no solo.

Ao descreverem, recentemente, a forma perfeita do fungo, Moraes et al. (1975), referiram ter sido ela obtida pelo cruzamento de seis culturas isoladas também do pêlo de ratos" silvestres (Proechimys guyannensis), apanhados nas vizinhanças de Belém, Estado ac Pará. Um dos autores deste trabalho tem conseguido também isolar o mesmo fungo do pêlo de ratos da mesma espécie, conhecidos como ratos espinhosos, capturados em área da floresta próximo a Santarém, Estado do Pará.

O difícil isolamento a partir do próprio chão da floresta, indica ser ele aí muito raro devido talvez, a uma escassez de ceratina. Aliás, é bem conhecida a pobreza em ceratinófilos das amostras do solo da floresta, contrastando com a relativa abundância dos mesmos no pêlo de animais silvestres, principalmente roedores, que nela vivem.

Os abrigos desses animais, pela quantidade mais elevada de ceratina que certamente deve existir em seu chão, oferecem, como no caso presente, maiores probabilidades para o isolamento de dermatófitos, do que qualquer outro ponto da floresta.

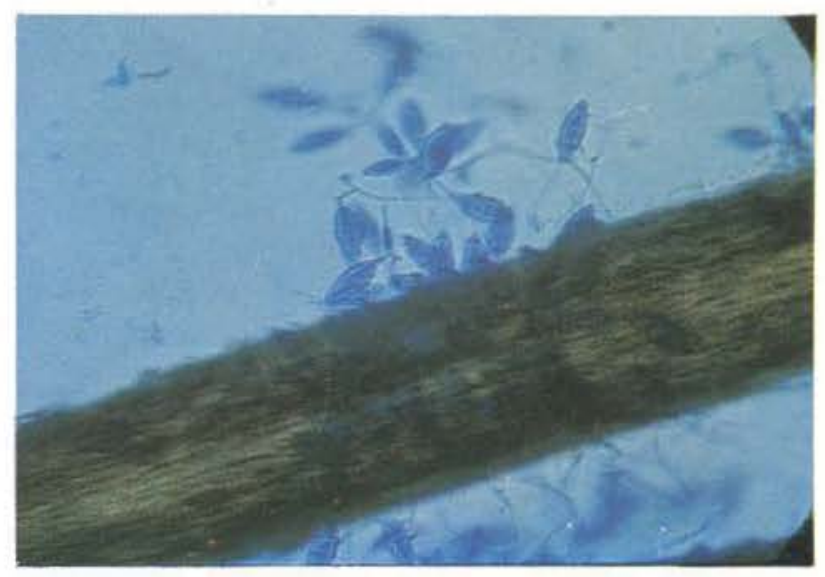

Fig. 3 - Colônia gigante em agar-Sabouraud, de Microsporum amazonicum.

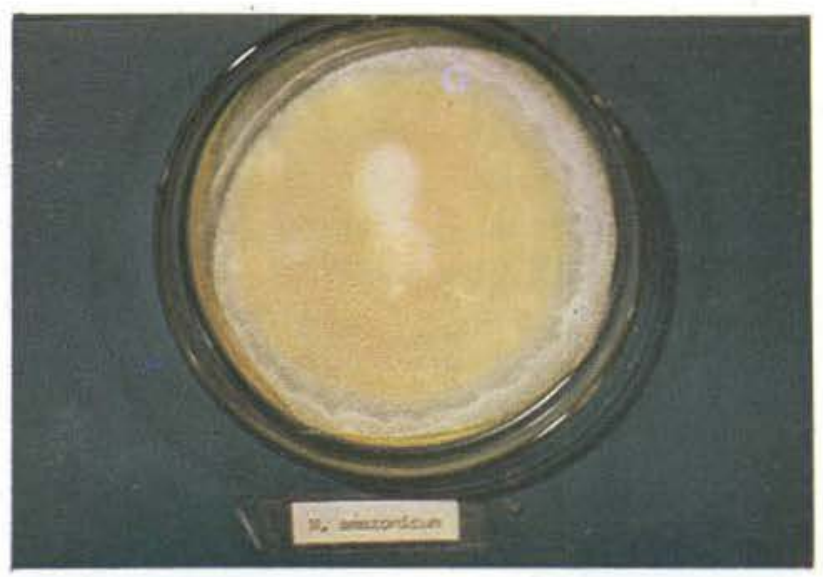

Fig. 4 - Microsporum amazonicum em pêlo humano. 


\section{SUMMARY}

The dermatophyte Microsporum amazonicum was first isolated by Moraes, et al. (1967), from the hair of a wild rat (Oryzomys sp.) trapped near the city of Manaus, State of Amazonas, Brasil. Since that time, it has been recovered several times from other wild rodents of the Amazon region, but not from the soil.

In this paper, the Authors report the isolation of M. amazonicum from the soil of a cave on the Manaus-Caracarav Highway, about $130 \mathrm{Kms}$. from Mianaus. This is the first time that this dermatho. phyte has been obtamed directly from the soil. Of 96 soil samples, colleted in the cave, 12 were found to be positive for Microsporum amazonicum.

Rarely found in the soil, this fungo appears to be restricted to the Amazon region. Reasons for its limited distribution are discussed.

\section{BIBLIOGRAFIA CITADA}

AJELLO, L

1968 - A taxonomic review of the dermathophytes and related species. Sabouraudia, $6: 147-159$
FONSECA, O.J.M.

1976 - Fungos ceratinofílicos no solo de Manaus. Acta Amazonica, 6:63-65

Moraes, M.; Borelli, D. \& Fed, M.

1967 - Microsporum amazonicum nova species. Medicina Cutanea (Barcelona), 2:201-205.

moraes, M.; Padhye, A.A. \& Ajello, L.

1975 - The perfect state of Microsporum amazonicum. Mycologia, 67 : 1109-1113.

VANLREUSEGHEM, $\mathrm{R}$.

1952 - Technique biologique pour l'isolement des dermstophytes du sol. Ann. Soc. Belge Mea. Trop., 32: 173-178.

VILETA, E.M. \& MORIES, M.

1962 - Isolamento de Microsporum gypseum e Trichophyton mentagrophytes do solo da cidade de Manaus, Amazonas. Rev. Inst. Med. Trop. S. Paulo, $4: 299-301$. 